\title{
Laparoscopic Extended Left Hemi-Hepatectomy plus Caudate Lobectomy for Caudate Lobe Hepatocellular Carcinoma
}

\author{
Hongyu $\mathrm{Li}^{1} \cdot$ Yonggang $\mathrm{Wei}^{2}$
}

Received: 7 July 2018 / Accepted: 9 September 2018 / Published online: 21 September 2018

(C) 2018 The Society for Surgery of the Alimentary Tract

\begin{abstract}
Background Laparosopic hepatectomy for caudate lobe is classified as one of the most difficult procedures to perform. ${ }^{1}$ For malignant caudate lobe tumor which is close to hepatic veins, extended hemi-hepatectomy may be more suitable.

Methods A 60-year-old man was diagnosed with hepatitis B virus infection-related hepatocellular carcinoma (HCC). His liver function was Child-Pugh A and ICG-15 test was $2.1 \%$. Abdominal CT showed a $5 \times 6 \mathrm{~cm}$ mass located in caudate lobe with middle and left hepatic vein encroached. Caudate lobectomy was not adopted because of the suspicious hepatic vein invasion by HCC. Instead, laparoscopic extended left hemi-hepatectomy plus caudate lobectomy was planned.

Results The patient was placed in supine position. Three 12-mm trocars and two 5-mm trocars were used. After fully mobilization, the caudate lobe was exposed. The third porta hepatis was dissected before parenchyma transection.. The cutline was along the right side of middle hepatic vein. Pringle maneuver ( $15 \mathrm{~min}$ clamping and $5 \mathrm{~min}$ release, total Pringle time was $60 \mathrm{~min}$ with 4 times clamping) was performed during transection. The superficial tissue was divided using ultrasonic shears, while the deeper tissue was divided using LigaSure. The left pedicle was dissected and transected meticulously. The main trunk of right hepatic vein was continuously exposed from the caudal side. A linear stapler was used to transect the middle and left hepatic vein from the root. Bipolar was used for hemostasis. The specimen was removed from suprapubic incision. The operation time was $200 \mathrm{~min}$ and estimated blood loss was $100 \mathrm{ml}$. HCC was confirmed by postoperative pathological examination. The postoperative course was uneventful.

Conclusions Laparoscopic extended left hemi-hepatectomy plus caudate lobectomy is feasible and safe for caudate lobe HCC with suspicious hepatic veins invasion.
\end{abstract}

Keywords Hepatocellular carcinoma $\cdot$ Laparoscopy $\cdot$ Extended left hemi-hepatectomy $\cdot$ Caudate lobectomy

\section{Abbreviations}

HCC Hepatocellular carcinoma

Electronic supplementary material The online version of this article (https://doi.org/10.1007/s11605-018-3970-z) contains supplementary material, which is available to authorized users.

Yonggang Wei

docweiyonggang@126.com

Hongyu Li

lihongyu1986@gmail.com

1 Department of Pancreatic Surgery, West China Hospital, Sichuan University, Chengdu 610041, Sichuan Province, China

2 Department of Liver Surgery, West China Hospital, Sichuan University, Chengdu 610041, Sichuan Province, China

\section{Compliance with Ethical Standards}

Conflict of Interest The authors declare that they have no conflict of interest.

\section{References}

1. Wakabayashi, G. et al. Recommendations for laparoscopic liver resection: a report from the second international consensus conference held in Morioka. Annals of surgery 261, 619-629, https://doi.org/10. 1097/SLA.0000000000001184 (2015). 